\title{
The assessment of holoprosencephaly cases in the last 10 years
}

\author{
Hulusi Goktug Gurer, Ozlem Ozgur Gursoy, Ceren Yildiz Eren \\ Obstetrics and Gynecology Clinic, Eskisehir Acibadem Hospital, Eskisehir, Turkey
}

Received: 2021-04-07.

Accepted: 2021-07-10

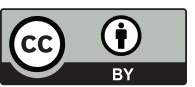

This work is licensed under a Creative Commons Attribution 4.0 International License

J Clin Med Kaz 2021; 18(4):91-94

Corresponding author:

Ceren Yildiz Eren.

E-mail: cyeren@yaani.com;

ORCID: 0000-0003-1648-3345

\begin{abstract}
Polyencephaly is a disorder characterized by a structural cleavage defect or inadequate differentiation of the forebrain. Chromosomal anomalies and environmental teratogenic factors play a role in its development. We reported 22 cases of holoprosencephaly diagnosed between the years 2011-2020 in our clinic.
\end{abstract}

Key words: holoprosencephaly, ultrasonography, chromosomal abnormality

\section{Introduction}

Holoprosencephaly (HPE) is a gastrulation disorder caused by the inadequate midline cleavage of the prosencephalon on the 18 th and the 28th day of gestation [1]. This leads to neurologic impairment of the brain associated with facial dysmorphism [2].

HPE is a complex brain malformation characterized by midline defects of the face resulting from incomplete division of the prozencephalon. The incidence of HPE is $1: 250$ during the embryonic period and is encountered in $1: 16000$ of all births and the etiology of this syndrome is extremely heterogeneous and remains to be elucidated. Generally, the division of the brain into different lobes and hemispheres occurs around the fourth week of pregnancy. In holoprosencephaly, this division, which has serious effects before and after birth, is not formed or completed. This condition is often accompanied by changes such as the presence of cranial and facial malformations, hypertelorism or coexistence of eyes, cyclopia, or just one eye, nose, cleft lip, cleft palate, or hydrocephalus [3].

Holoprosencephaly is a developmental defect characterized by advanced facial anomalies that occur as a result of deficient separation of the cerebral hemispheres into the 2 lobes. The disease is separated into 3 groups according to its severity: alobar, semilobar and lobar type. While cyclopia and agenesis of premaxillary are facial findings in the most severe cases, microcephaly and hypotheleorism are encountered in mild severe cases [4].
The term of HPE was proposed by Zeman and Demyer in 1963. They classified HPE into three types: alobaric, semilobaric, and lobar, based on the degree of separation of the hemispheres and the existence of an interhemispheric fissure [5].

Severe anomalies of both the face and the brain are observed as a result of an embryological defect. In the alobar form, the most severe form, there is a single ventricle instead of the ventricular system and the brain is small. In addition to fusion in the thalamus, there was also fusion in the corpus striatum. The corpus callosum, falx cerebri, optic chiasma and bulbus olfactorius are absent. The midbrain and brainstem are normal. Partial fusion of the thalamus and partial segmentation of the ventricles are observed in the semi-lobar form, which is the intermediate form. The corpus callosum and olfactor protrusions are usually absent. The lobar form is the lightest. Hemispheres are generally well separated and brain appearance is more normal. Lateral ventricles are wide. The corpus callosum may or may not be present or may be hypoplastic. However, septum pellucidium has not developed even in the lobar type considered to be the mildest. Therefore, the absence of septum pellucidium in distinguishing from hydrocephalus on ultrasonography in the intrauterine period is a finding used in the differential diagnosis. In 1993, Barkovich and Quint described a new variant named middle "interhemispheric" or "syntelencephaly" [6]. 
The foremost extreme form is the alobar HPE, in which a total lack of cleavage of the cortex is seen due to diffuse cortical nonseparation. Ultrasonography (USG) reveals a single ventricular cavity with fused thalami and the existence of interhemispheric fissure, corpus callosum, falx, olfactory bulbs and optic tracts. Mid-facial defects are cyclopia, ethmocephaly, cebocephaly, proboscis-like nasal structure, cleft lip/palate, and hypotelorism. The semilobar form occurs as a result of the nonseparation of the frontal lobes. During USG examination, the partially formed occipital horns of the ventricles, the posterior parts of the falx and interhemispheric fissures can be observed. The thalami could only be partly fused. The ventricles are fused, and the anterior portion of the brain lacks the corpus callosum, optic tract, and olfactory bulb. The facial defects are cyclopia, milder and ethmocephaly are usually not observed. Nonseparation of the basal part of the frontal lobes is encountered in the lobar HPE. In this, only ventricular horns and a part of the frontal lobes are fused. The interhemispheric fissures, corpus callosum and falx are not completely developed, and the roof of the anterior end of the frontal horn appears square. For new variant, nonseparation of the posterior frontal and parietal lobes are identified [7].

HPE is a heterogeneous disorder $30-40 \%$ of which has a chromosomal disorder. The hedgehog signaling pathway takes part in morphogenesis during the gastrulation period. Loss of function or mutations in this pathway are known to cause recurrent HPE. It is generally associated with chromosome 13 abnormality (trisomy 13, deletion or duplication of 13q, or ring 13). Other trisomies, deletion $2 \mathrm{p}$, duplication $3 \mathrm{p}$, deletion $7 \mathrm{q}$, etc., are other determined defects. HPE can also be encountered in multiple syndromes, including Oral-facial-digital syndrome type VI, Meckel's syndrome, Smith-Lemli-Opitz syndrome and Pallister-Hall Syndrome. In addition, approximately $1-2 \%$ of HPE fetuses were reported to have diabetic mothers. Mendelian inheritance can also be seen in isolated cases. These are more often transmitted with an autosomal dominant trait for which four genes have been identified [8]. We present 22 cases of holoprosencephaly diagnosed between the years 2011-2020 in our clinic combined with the previous literature review.

\section{Material and methods}

In this retrospective analysis, HPE cases, diagnosed between April 2011 and September 2020, were enrolled. Detailed second trimester USG examinations were conducted with GE Medical Systems, Voluson 730 Expert, Voluson E8, Zipf, Austria, equipped with a volumetric convex transducer from 4 to $8 \mathrm{MHz}$ by a professor of perinatology with 30 years of experience. Fetal MRI scan results were reported by a radiology professor with 30 years of experience in neurology. Prenatal genetic analyzes were made by the genetic department of our institution. Institution's Ethics Committee endorsed this study. The consent of the subjects was obtained according to the Helsinki Declaration. All cases but one were detected during the second trimester. After USG diagnosis of holoprosencephaly, all cases were genetically tested by amniocentesis after 16 th weeks of gestation. All cases were referred to radiology at around 20 weeks of gestation for the confirmation of the diagnosis with MRI. According to the legislation of our country, abnormal fetuses could be terminated after the confirmed diagnosis with the multidisciplinary decision (obstetrics, pediatrics and radiology) till 24 weeks of gestation. So, we terminated the pregnancies before 24 weeks of gestation, after taking approval of the parents with the written consent form.

\section{Results}

In the 10-year period between April 2011 and September 2020, we assessed 9200 routine patients in the second trimester. HPE was detected in 22 cases $(0.23 \%)$. The mean age of cases was $29 \pm 2.3$ (20-38) years. The average gestational period at the time of detection was 21 weeks (12 to 22 weeks). All mothers were Caucasian with mean gravity $2 \pm 0.8$ [1-5]. Five of them had consanguineous marriages. Twelve mothers were smokers. Four pregnant women had Type II diabetes mellitus with an average duration of 3 (2-5) years. Two pregnant women had Type I diabetes mellitus with a mean duration of $8(5-11)$ years. None of the cases had the potential teratogenic disease, exposure to radiation or abuse of toxic substances during the 1st and second trimester of the pregnancy. Besides, two cases had a familial history of congenital malformation, one of them had a fetus with recurrent HPE.

All cases but one were detected during the second trimester. The karyotype was obtained from the prenatal amniotic fluid sample in all cases with the indication of abnormal second trimester ultrasonographic findings. 15 fetuses with HPE were chromosomally normal, but one fetus had trisomy 18 (case 19), the rest six was trisomy 13 (case 1, 7, 9, 13, 21, 22). All chromosomally abnormal cases $(68.1 \%)$ were found to have isolated findings. Chromosomally normal three fetuses had pes equinovarus (case 2, 11, 12). Three fetuses with trisomy 13 had ventricular septal defect, pes equinovarus and hypotelorism, two fetuses had hyperechogenic bowel and a single umbilical artery.

Figure 1 -Case 19; Alobar HPE

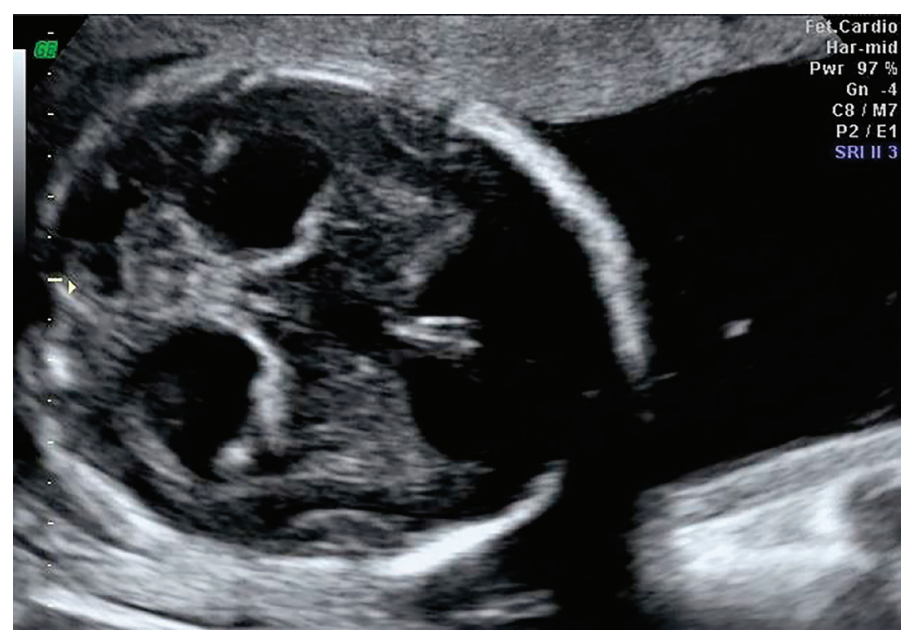

Figure 2 -Case 19; Alobar HPE

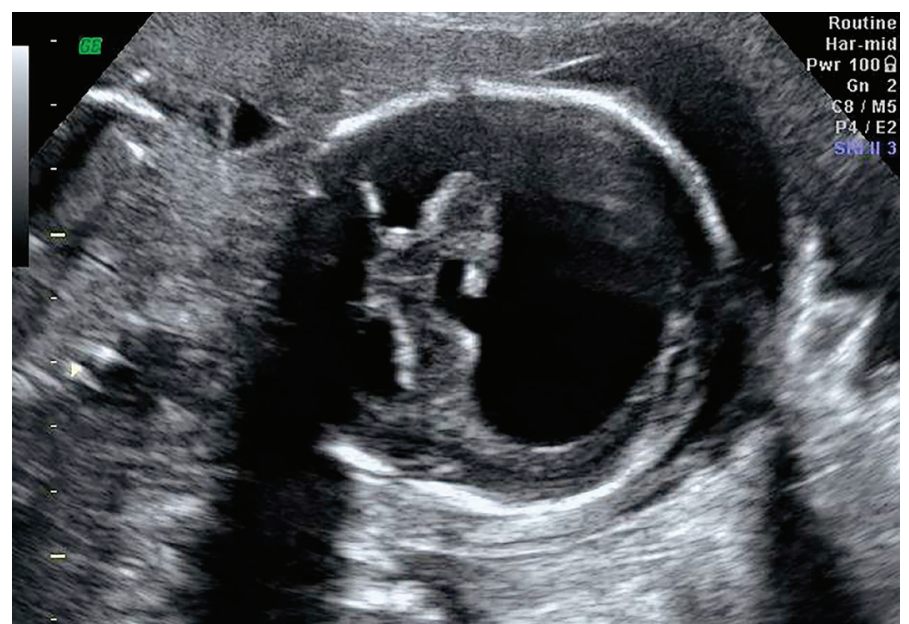


Figure 3 -Case 2; Semilobar HPE

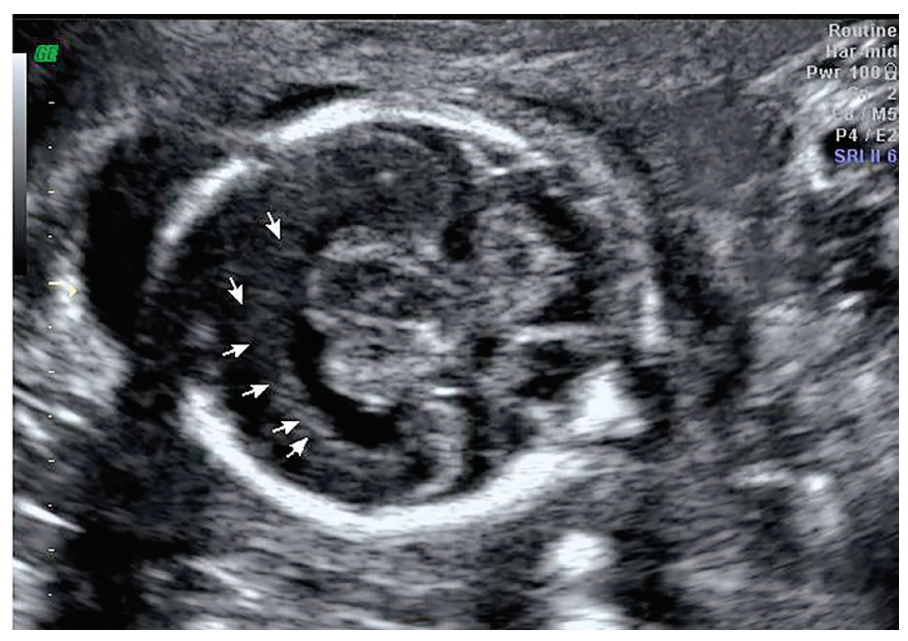

Trisomy 18 fetus had cleft lip and palate with ventricular septal defect and microphthalmia. In accordance with the literature, we found out that 4 cases were alobar HPE, 3 of them were lobar HPE, and the remaining 15 were classified as semilobar HPE. The USG findings of alobar HPE of our case 19 are shown in Figure 1 and 2, and of semilobar HPE of case 2 in Figure 3 and 4.

All fetuses were terminated after confirmation with MRI and prenatal genetic diagnosis. Twelve cases were females, and 10 were males $(54.5 \%$ vs. $45.5 \%)$.

\section{Conclusion}

The larger of HPE cases are sporadic. This is important as it demonstrates that routine obstetric sonography is likely an imperative prenatal diagnostic tool. HPE's first prenatal diagnosis was conducted by Kurtz et al. in 1980 [9]. With the development of ultrasound, early diagnosis of HPE has become possible as early as nine weeks for alobar HPE. The earliest diagnosis of semilobar HPE was conducted at the 13th week [10]. Also, HPE is associated with $16 \%$ or more of hydrocephalus cases diagnosed prenatally [11]. In accordance with the literature, one of our cases was detected at 13 weeks' of gestation during transvaginal ultrasonographic approach because of abortus imminence.

The precise causes of HPE have not yet been defined in an accurate way. However, some maternal factors have been identified, including maternal diabetes, cytomegalovirus infection, ethanol, salicylate, aspirin, antiepileptics, misoprostol, retinoic acid, methotrexate and intrauterine exposure to cholesterol-lowering drugs [12]. In our study, there was no drug exposure, but six $(27.2 \%)$ cases were associated with maternal diabetes.

Karyotyping technique isn't required for diagnosing HPE, but knowledge of a chromosomal abnormalities can impact patient counseling. Most cases of HPE are related to a syndrome and approximately between $40 \%$ and $60 \%$ of fetuses with HPE have trisomy 13 (Patau syndrome) which is the most ordinary etiology of HPE [8]. Other related nonrandom chromosomal abnormalities are trisomy 18 (Edwards syndrome), 21 (Down's syndrome). $18-25 \%$ of them have monogenic syndrome like Pallister-Hall, Smith-Lemli-Opitz, Rubinstein-Taybi syndromes and structural anomalies including 13q, 18p, 7q36, 3p24-pter, 2p21, 21q22.3. The most commonly studied genes are Sonic Hedgehog (SHH), SIX3, ZIC2 but SHH is the first HPE gene recognized from this perspective [13]. Around $75 \%$ of HPE patients with normal chromosomal don't have identifiable Journal of Clinical Medicine of Kazakhstan: 2021 Volume 18, Issue 4
Figure 4 -Case 2; Semilobar HPE

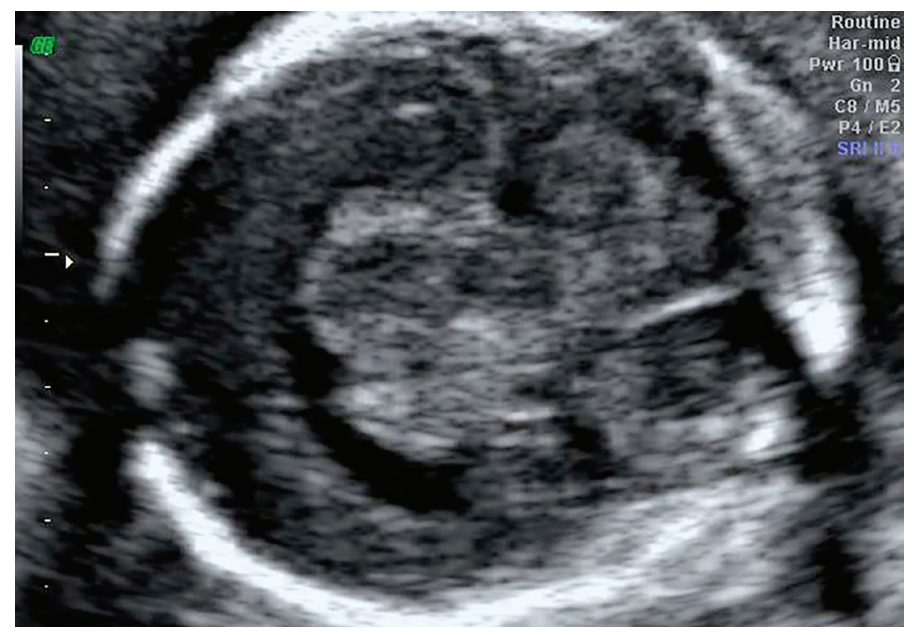

mutations in any of the genes studied. We found $31.8 \%$ chromosomal abnormality and $85.7 \%$ of them were trisomy 13 .

In a perinatal study conducted in California, 56 alobar HPE (46\%), 24 semilobar HPE (20\%) and 11 lobar HPE (9\%) cases were detected and 30 specimens had an undetermined HPE type [13]. In separate study, it was stated that 360 of 1750 cases with fetal anomalies diagnosed prenatally by ultrasound had central nervous system anomalies. Thirty fetuses were involved in the study group of HPE with facial anomalies. In this study, there were 18 alobar HPE (60\%), 5 semilobar HPE (17\%), and 2 lobar HPE (6.7\%) cases [2]. In our study, we found out 54 alobar HPE (60\%), 15 semilobar HPE (17\%), and 3 lobar HPE (6.7\%) cases.

Because of the association between facial abnormalities and HPE, the expression "the face predicts the brain" is often used. Nearly $80 \%$ of HPE has distinctive fascial abnormalities. For the remaining 20\%, the facial features are non-diagnostic [14]. In $81.8 \%$ of our cases, characteristic facial abnormalities including cyclopia, cleft lip and/or palate are present.

The prognosis of infants born with HPE is uniformly poorer and consistent with the severity of the brain malformation. That is why management is challenging as a multidisciplinary team is needed. Microcephaly is usually defined, but if hydrocephalus develops it may result in macrocephaly. Microcephaly is mostly present in semilobar and lobar HPE, whereas hydrocephalus is usually the problem of alobar patients. Difficulty swallowing and instability of body temperature, respiration, and heart rate are common during seizures. Endocrinopathies, diabetes insipidus, growth hormone deficiency, hypocortisolism and hypothyroidism affect morbidity and mortality. Also, twothirds of the patients with alobar HPE and semilobar HPE needed a gastrostomy tube due to feeding difficulties [15]. As a result, we have to be sure about the parents being aware of the disease before decision. All of our parents gave consent for the termination of the pregnancies.

The most excellent diagnostic procedure of HPE is the ultrasound. Typical findings in the first trimester are the existence of a midline monoventricle and the lack of the typical echogenic "butterfly" sign based on the choroid plexuses. Fetal MRI assists in enabling a more sensitive diagnosis for milder forms of HPE in the 3rd trimester [16]. Especially semilobar and lobar HPE should be distinguished from septo-optic dysplasia and corpus callosum agenesis. In some studies comparing the accuracy of USG and MRI for significant fetal neurological abnormalities, USG and MRI were consistent in 109 of 126 cases $(86.5 \%)$, allowing for accurate diagnosis [17]. We confirmed our diagnoses with MRI in all cases. 
It is concluded that HPE is a rare brain malformation usually related with facial anomalies. USG helps in the early detection of these malformations, while karyotype analysis strengthens the diagnosis. The documentation of such rare anomalies would be helpful in further detailed studies.
Disclosures: There is no conflict of interest for all authors.

Acknowledgements: We thank Prof. Turgay Sener, M.D. for the use of the data generated by him and his support to this manuscript.

\section{Funding: None.}

\section{References}

1. Orioli IM, Castilla EE. Epidemiology of holoprosencephaly: Prevalence and risk factors. Am J Med Genet C Semin Med Genet. 2010; 154(1):13-21. doi: 10.1002/ajmg.c.30233.

2. Blaas HG, AG Eriksson AG, KA Salvesen KA, CV Isaksen CV, B Christensen B, G Møllerløkken G et al. Brains and faces in holoprosencephaly: pre- and postnatal description of 30 cases. Ultrasound Obstet Gynecol. 2002; 19(1):24-38 . doi: 10.1046/j.09607692.2001.00154.x.

3. Raam MS, Solomon BD, Muenke M. Holoprosencephaly: a guide to diagnosis and clinical management. Indian Pediatr. 2011; 48(6):457-466. doi: 10.1007/s13312-011-007.

4. Cohen Jr MM. An update on the holoprosencephalic disorders. The Journal of pediatrics. 1982; 101(5):865-9. https://doi.org/10.1016/ S0022-3476(82)80349-1

5. Demyer W, Zeman W. Alobar holoprosencephaly (arhinencephaly) with median cleft lip and palate: clinical, electroencephalographic and nosologic considerations. Confin Neurol. 1963; 23:1-36. doi: 10.1159/000104278.

6. Barkovich AJ, Quint DJ. Middle interhemispheric fusion: an unusual variant of holoprosencephaly. AJNR Am J Neuroradiol. 1993; 14(2):431-440.

7. Ionescu CA, Calin D, Navolan D, Matei A, Dimitriu M, Herghelegiu C et at. Alobar holoprosencephaly associated with a rare chromosomal abnormality: Case report and literature review. Medicine. 2018; 97(29):e11521. doi: 10.1097/MD.0000000000011521.

8. Kruszka P, Martinez AF, Muenke M. Molecular testing in holoprosencephaly. Am J Med Genet C. 2018; 178(2):187-193. https://doi. org/10.1002/ajmg.c.31617.

9. Kurtz AB, Wapner RJ, Rubin CS, Cole-Beuglet C, Ross RD, Goldberg BB. Ultrasound criteria for in utero diagnosis of microcephaly. J Clin Ultrasound. 1980; 8(1):11-16. doi: 10.1002/jcu.1870080104.

10. Blaas HG, Eik-Nes HS, Vainio T, Isaksen CV. Alobar holoprosencephaly at 9 weeks gestational age visualized by two- and threedimensional ultrasound. Ultrasound Obstet Gynecol. 2000; 15:62-65. doi: 10.1046/j.1469-0705.2000.00005.x.

11. Levey EB, Stashinko E, Clegg NJ, Delgado MR. Management of children with holoprosencephaly. Am J Med Genet Part C Semin Med Genet. 2010; 154(1):183-190. https://doi.org/10.1002/ajmg.c.30254

12. Herghelegiu D, Ionescu CA, Pacu I, Bohiltea R, Herghelegiu C, Vladareanu S. Antenatal diagnosis and prognostic factors of aneurysmal malformation of the vein of Galen: a case report and literature review. Medicine (Baltimore). 96:e7483-8, 2017. doi.org/10.1097/ MD.0000000000007483

13. Croen LA, Shaw GA, Lammer EJ, "Holoprosencephaly: epidemiologic and clinical characteristics of a California population," Am $J$ Med Genet. 1996; 64:465-472. doi: 10.1002/(SICI)1096-8628(19960823)64:3<465::AID-AJMG4>3.0.CO;2-O.

14. Plawner LL, Delgado MR, Miller VS, Levey EB, Kinsman SL, Barkovich AJ et al. Neuroanatomy of holoprosencephaly as predictor of function: beyond the face predicting the brain. Neurology. 2002; 59:1058-1066. doi: 10.1212/wnl.59.7.1058.

15. Hahn JS, Plawner LL. Evaluation and management of children with holoprosencephaly. Pediatr Neurol. 2004; 31:79-88. doi: 10.1016/j. pediatrneurol.2004.03.006.

16. Timor-Trisch IE, Monteguado A, Santos R. Three-dimensional inversion rendering in the first- and early second-trimester fetal brain: its use in holoprosencephaly. Ultrasound Obstet Gynecol. 2008; 32:744-750. https://doi.org/10.1002/uog.6245

17. Barr M, Cohen MM. Holoprosencephaly survival and performance. Am J Med Genet. 1999; 89:116-120. https://doi.org/10.1002/ (SICI)1096-8628(19990625)89:2<116::AID-AJMG10>3.0.CO;2-4 